\title{
Impact of diabetes continuing education on health care professionals' attitudes towards diabetes care in a Yemeni city
}

\author{
Ibrahim Sales ${ }^{1}$, Salmeen D Babelghaith¹, Syed Wajid', Mansour A Mahmoud², \\ Suhair S Alsaleh ${ }^{3}$, Saeed Alfadly", Weal H Mancy ${ }^{1}$, Mohammed N Al-Arifi', \\ Mohammed Saif Anaam² \\ ${ }^{1}$ Clinical Pharmacy Department, College of Pharmacy, King Saud University, ${ }^{2}$ Department of Clinical and Hospital \\ Pharmacy, College of Pharmacy, Taibah University, Al-Madinah Al-Munawwarah, ${ }^{3}$ Ministry of Health, Riyadh, ${ }^{4}$ Qassim \\ University, Unaizah College of Pharmacy, Saudi Arabia
}

*For correspondence: Email: wali@ksu.edu.sa; Tel: +966554286827, 0096614677353; Fax: 0096614674229

Sent for review: 20 June 2017

Revised accepted: 26 October 2017

\begin{abstract}
Purpose: To evaluate the impact of a continuing education (CE) program on the attitudes of health care professionals (HCPs) towards diabetes care in Yemen.

Methods: A pre- and post-intervention study was carried out in Mukalla City, Hadramout, Yemen and was offered to all physicians, pharmacists, and nurses registered in the Health Office in the Mukalla City. The HCPs were invited to attend a CE program. All participants filled out a questionnaire before the intervention (pre-test) that measured the attitudes of the participants towards diabetes. An interventional program was given in the form of a seminar, and participants were requested to complete the same questionnaire after the seminar.

Results: A total of $73 \mathrm{HCPs}$ attended the CE, including 19 pharmacists (26\%), 37 physicians (50.7\%), and $17(23.3 \%)$ nurses. The pre- and post-intervention changes in the questionnaire responses were significant only for attitude toward the values of blood glucose levels $(p=0.009)$ and attitude toward autonomy of diabetes patients $(p=0.023)$.

Conclusion: HCPs in Mukalla City have positive attitudes toward diabetes. Physicians were more aware of the sequelae of diabetes than other healthcare professional groups with nurses showing the least understanding. Therefore, more emphasis should be placed upon designing education programs for diabetes specifically tailored for nurses and pharmacists.
\end{abstract}

Keywords: Diabetes, Continuing education, Attitude, Health care professionals

\begin{abstract}
This is an Open Access article that uses a funding model which does not charge readers or their institutions for access and distributed under the terms of the Creative Commons Attribution License (http://creativecommons.org/licenses/by/4.0) and the Budapest Open Access Initiative (http://www.budapestopenaccessinitiative.org/read), which permit unrestricted use, distribution, and reproduction in any medium, provided the original work is properly credited.

Tropical Journal of Pharmaceutical Research is indexed by Science Citation Index (SciSearch), Scopus, International Pharmaceutical Abstract, Chemical Abstracts, Embase, Index Copernicus, EBSCO, African Index Medicus, JournalSeek, Journal Citation Reports/Science Edition, Directory of Open Access Journals (DOAJ), African Journal Online, Bioline International, Open-J-Gate and Pharmacy Abstracts
\end{abstract}

\section{INTRODUCTION}

Although the prevalence of diabetes mellitus (DM) is spiraling to epidemic proportions, healthcare providers still continue to struggle with providing optimal care and education throughout the world [1,2] . Individuals with DM need systematic monitoring by a collaborative healthcare team providing the patient with the tools necessary to manage the disease with 
emphasis on patient self-care. Diabetes selfmanagement education (DSME) is fundamental to inform, motivate, and support healthcare professionals (HCP), as well as to help patients live with their chronic condition [3]. The goals of DSME are to reduce the number of diseaserelated complications, improve patient quality of life, and improve metabolic control [4].

Previous studies [5] reported that deficiencies in knowledge about the pathophysiology and symptoms of the disease create difficulties for disease state management. These barriers can ultimately be connected to factors exclusive to both patients and the health system. This indicates the need for HCPs to reevaluate and/or restructure treatment approaches for patients with diabetes in light of both biological and social factors and existing resources. Moreover, research has shown that knowledge alone does not guarantee a change in the behavior of either patients or healthcare providers [6-10].

DSME programs have been identified as an impetus for a change in the attitudes of patients and healthcare providers, respectively [11-13]. Results from previously published studies investigating the attitudes of HCPs and patients demonstrate that there is a need for HCPs to undergo specialized diabetes training and education $[6,11,12,14]$. This indicates that HCPs recognize the magnitude and difficulties of managing the disease and their inadequacy in addressing the numerous biopsychosocial factors associated with its management.

However, different HCPs have divergent attitude patterns towards diabetes. For example, pharmacists generally have more positive attitudes towards diabetes $[6,11,15-17]$ compared to nurses and others [14]. Furthermore, it has been determined that pharmacists' knowledge and attitudes toward diabetes may significantly influence patient outcomes [18]. Physicians and pharmacists indicated slightly positive attitudes [6]. In addition, one study revealed that nurses had the least favorable attitude towards diabetes. These results suggest that improving the attitudes of HCPs may lead to improved clinical outcomes.

The burden of DM is astronomical upon the health sector in low- and middle-income countries. Extraordinary efforts are required from all HCPs to prevent diabetes-related morbidity and mortality $[19,20]$.

Therefore, the objective of the present study was to evaluate the impact of a continuing education
(CE) program and determine the attitude towards diabetes among HCPs in Yemen.

\section{METHODS}

\section{Design}

A pre- and a post-intervention study conducted in Mukalla City, Hadramout, Yemen among HCPs including medical physicians, pharmacists, and nurses.

\section{Sample size}

The target population for this study included all physician, pharmacists, and nurses registered in the Health Office of the Mukalla City, the capital of Yemen's Hadramout governorate. According to the Health Office in Hadramout, the total number of specific HCPs at the time of the study was 291 physician, 45 pharmacists, and 100 nurses. Therefore, the total population size for this study was 436. Raosoft Inc. software was used to estimate the sample size. With an error rate of 5 and $95 \%$ confidence levels, the minimum required sample size was 205 HCPs. Considering the possibility of a low response rate, the study selected 300 HCPs using a stratified random selection method where the population of HCPs was divided into subgroups (i.e., physicians, nurses, and pharmacists) before selection. The HCPs were invited to attend the CE using a special invitation card.

\section{Ethical considerations}

This study fallowed international ethical guidelines for health related research involving humans [21]. In addition, ethical approval was obtained from the ethics committee division of the Hadramout branch of Ministry of Health (no. $1 / 2009)$. On the day of the CE program, all participants were briefed on the study and its objectives. They were told that they had to attend the CE program and complete a pre-and post-test questionnaire in order to be eligible to participate in the study. In addition, they were informed about the follow-up that would be conducted up to 6 months after the program. Participants who consented to participate in the study were asked to write their name, working address, and signature. Non-participants who declined to participate in the research were still permitted to attend the CE.

\section{Description of intervention}

All participants completed a questionnaire before the intervention (pre-test). This questionnaire was used to measure the general knowledge, 
attitudes, and practices of the participants regarding diabetes. After the pre-test, an interventional program was delivered in the English language. This program included an extensive information about the pathophysiology of diabetes, diagnosis, signs and symptoms, complications, review of the medication classes, patient monitoring, and self-care.

The lecture discussed the disease state including the diagnostic approach, signs and symptoms, various laboratory investigations, insulin and non-insulin pharmacotherapy, aspects of patient education (including dietary control, medications, foot care physical exercise, and self-monitoring blood glucose levels), and diabetes complications (such as nephropathy, retinopathy, neuropathy, macrovascular complications, lipid abnormalities, and diabetic foot ulcers).

\section{Diabetes attitude measurement}

The diabetes attitude scale (DAS) was modified from the Third Version (DAS-3) developed by Anderson et al [22]. The original version of the DAS-3 had 33 items. All the items in DAS-M were scored on a 5-point Likert scale: strongly disagree, disagree, neutral, agree, and strongly agree. For the positive questions, the scores for the Likert scale were 1 (strongly disagree) to 5 (strongly agree) and for the negative questions, the scores were the reverse of the positive questions. The total score was calculated by dividing the sum of the score by the total number of items in the subscales.

Each of the five subscales contained five to eight items. The total number of items in the subscales was 30 questions. The subscales addressed various topics including the need for special training, feelings related to the seriousness of type 2 diabetes, the value of tight blood glucose control, the psychosocial impact of diabetes, and patient autonomy.

Finally, after the pilot test, Cronbach's alpha validity for the questionnaire was 0.754 after the deletion of three items.

\section{Data analysis}

The data were analyzed using SPSS version 15 for Windows (SPSS). Both descriptive and inferential statistics were applied. For the descriptive analysis, results were expressed as numbers, percentages, and means $( \pm$ SD and 95 $\% \mathrm{Cl}$ ). Wilcoxon signed rank test was used to compare the differences between preintervention and post-intervention, and the Mann-
Whitney $U$ and Kruskal-Wallis tests were used to assess intergroup differences.

Repeated Mann-Whitney with Bonferroni's adjustment method was utilized to determine differences between subgroups.

\section{RESULTS}

A total of 73 of health care professionals attended the CE. Out of 73 healthcare providers, there were 37 physicians $(50.7 \%), 19$ pharmacists (26\%), physician and 17 (23.3\%) nurses.

\section{Changes in attitude scores among healthcare professionals}

Table 1 shows the changes in the attitude scores for the pre- and post-tests for each subscale. The changes were significant only for the attitude towards the value of blood glucose $(p=0.009)$ and attitude towards the autonomy of patients with diabetes $(p=0.023)$.

Table 1: Comparison of diabetes attitude scores for healthcare professionals at baseline and postintervention

\begin{tabular}{lccc}
\hline Subscale & $\begin{array}{c}\text { Pre-test } \\
\text { mean } \\
\text { (median) }\end{array}$ & $\begin{array}{c}\text { Post-test } \\
\text { mean } \\
\text { (median) }\end{array}$ & $\begin{array}{c}{ }^{*} \boldsymbol{P} \text { - } \\
\text { value }\end{array}$ \\
\hline $\begin{array}{l}\text { Special } \\
\text { training }\end{array}$ & $4.2(4.4)$ & $4.5(4.35)$ & 1.00 \\
$\begin{array}{l}\text { Seriousness } \\
\text { of diabetes }\end{array}$ & 2.99 & $3.1(3.1)$ & 0.111 \\
$\begin{array}{l}\text { Value of tight } \\
\text { blood }\end{array}$ & $3.3(3.0)$ & $3.7(3.6)$ & 0.009 \\
$\begin{array}{l}\text { glucose } \\
\begin{array}{l}\text { Psychosocial } \\
\text { impact of } \\
\text { diabetes }\end{array}\end{array}$ & $3.5(3.7)$ & $3.6(3.7)$ & 0.098 \\
$\begin{array}{l}\text { Autonomy of } \\
\text { diabetes for } \\
\text { patient }\end{array}$ & $3.3(3.4)$ & $3.6(3.6)$ & 0.023 \\
\hline *Wilcoxon test & & & \\
\hline
\end{tabular}

\section{Diabetes attitude scores of HCPs at pre- intervention}

Table 2 shows the mean and median of attitude subscale scores of healthcare professional groups at pre-test. As regards to the first subscale on the need for special training, all healthcare professional groups (physicians, pharmacists, physician, and nurses) agreed upon this necessity (mean $=4.2$ ). There were no significant differences among the attitudes of the HCPs in any of the five subscales in this study. 
Table 2: Diabetes attitude score of health care professional groups at baseline

\begin{tabular}{llcc}
\hline Item & $\begin{array}{l}\text { Healthcare } \\
\text { professionals' } \\
\text { category }\end{array}$ & $\begin{array}{c}\text { Pre-test } \\
\text { mean } \\
\text { (median) }\end{array}$ & $\begin{array}{c}{ }^{*} \boldsymbol{P} \text { - } \\
\text { value }\end{array}$ \\
\hline Special & Pharmacists & $4.2(4.2)$ & \\
training & Physician & $4.2(4.4)$ & 0.897 \\
& Nurses & $4.2(4.4)$ & \\
Seriousness & Pharmacists & $2.9(3.1)$ & \\
of diabetes & Physicians & $3.2(3.1)$ & 0.57 \\
& Nurses & $2.6(2.7)$ & \\
Value of tight & Pharmacists & $3.3(3.2)$ & \\
blood & Physicians, & $3.4(3.6)$ & 0.55 \\
glucose & Nurses & $3.4(3.6)$ & \\
Impact of & Pharmacists & $3.4(3.6)$ & \\
diabetes & Physician & $3.7(3.7)$ & 0.95 \\
& Nurses & $3.4(3.1)$ & \\
Autonomy of & Pharmacists & $3.0(3.7)$ & \multirow{2}{*}{0.859} \\
diabetes for & Physician & $3.4(3.5)$ & 0.859 \\
patient & Nurses & $3.3(3.3)$ & \\
\hline *Kruskal-Wallis & & & \\
& & &
\end{tabular}

\section{Changes in attitude scores among healthcare} professional groups

This study indicated that all HCP groups attained the same improvement in attitude scores at postintervention. This increase was not significant except for the pharmacists in the subscale highlighting the seriousness of diabetes $(p=$ 0.015 ), and pharmacists and physicians in the subscale related to the value of tight blood glucose control $(p=0.042$ and $p=0.012$ respectively), as shown in Table 3.

\section{Changes in attitude score of healthcare professionals groups (post-test)}

The Kruskal-Wallis test was performed to determine the differences in the attitude scores between healthcare professional groups. This study found statistically significant differences in subscales for the seriousness of diabetes $(p=$ 0.001 ) and the value of tight blood glucose control $(p=0.002)$, as shown in Table 4.

Repeated Mann-Whitney $U$ tests with Bonferroni's adjustment method was used with a significant level of 0.017 and found a significant difference between physicians and nurses $(p=$ 0.001 ) on the seriousness of diabetes subscale.

Table 4: Change in diabetes attitude scores among healthcare professional groups at post-test

\begin{tabular}{|c|c|c|c|}
\hline Item & HCP category & $\begin{array}{c}\text { Post-test } \\
\text { mean } \\
\text { (median) }\end{array}$ & $\begin{array}{c}{ }^{*} \boldsymbol{P} \text { - } \\
\text { value }\end{array}$ \\
\hline $\begin{array}{l}\text { Special } \\
\text { training }\end{array}$ & $\begin{array}{l}\text { Pharmacists } \\
\text { Physicians } \\
\text { Nurses }\end{array}$ & $\begin{array}{l}4.3(4.4) \\
4.4(4.6) \\
4.1(4.2)\end{array}$ & 0.092 \\
\hline $\begin{array}{l}\text { Seriousness } \\
\text { of diabetes }\end{array}$ & $\begin{array}{l}\text { Pharmacists } \\
\text { Physicians } \\
\text { Nurses }\end{array}$ & $\begin{array}{l}3.1(3.0) \\
3.3(3.3) \\
2.8(2.8)\end{array}$ & 0.001 \\
\hline $\begin{array}{l}\text { Value of tight } \\
\text { blood glucose }\end{array}$ & $\begin{array}{l}\text { Pharmacists } \\
\text { Physicians } \\
\text { Nurses }\end{array}$ & $\begin{array}{l}3.7(3.6) \\
3.8(3.9) \\
3.3(3.4)\end{array}$ & 0.002 \\
\hline $\begin{array}{l}\text { Impact of } \\
\text { diabetes }\end{array}$ & $\begin{array}{l}\text { Pharmacists } \\
\text { Physicians } \\
\text { Nurses }\end{array}$ & $\begin{array}{l}3.7(3.6) \\
3.7(3.8) \\
3.4(3.2)\end{array}$ & 0.063 \\
\hline $\begin{array}{l}\text { Autonomy of } \\
\text { diabetes for } \\
\text { patient }\end{array}$ & $\begin{array}{l}\text { Pharmacists } \\
\text { Physicians } \\
\text { Nurses }\end{array}$ & $\begin{array}{l}3.7(3.7) \\
3.7(3.6) \\
3.4(3.4)\end{array}$ & 0.06 \\
\hline
\end{tabular}

*Kruskal-Wallis Test

Table 3: Changes in diabetes attitude scores within health care professional groups from pretest to posttest

\begin{tabular}{|c|c|c|c|c|}
\hline Item & HCP category & $\begin{array}{c}\text { Pre-test mean } \\
\text { (median) }\end{array}$ & $\begin{array}{c}\text { Post-test mean } \\
\text { (median ) }\end{array}$ & ${ }^{\star} P$-value \\
\hline \multirow[t]{3}{*}{ Special training } & Pharmacists & $4.2(4.2)$ & $4.3(4.4)$ & 0.261 \\
\hline & Physicians & $4.2(4.4)$ & $4.4(4.6)$ & 0.153 \\
\hline & Nurses & $4.2(4.4)$ & $4.1(4.2)$ & 0.41 \\
\hline \multirow{3}{*}{$\begin{array}{l}\text { Seriousness of } \\
\text { diabetes }\end{array}$} & Pharmacists & $2.9(3.1)$ & $3.1(3)^{\prime}$ & 0.015 \\
\hline & Physicians & $3.2(3.1)$ & $3.3(3.3)$ & 0.359 \\
\hline & Nurses & $2.6(2.7)$ & $2.8(2.8)$ & 0.051 \\
\hline Value of tight & Pharmacists & $3.3(3.2)$ & $3.7(3.6)$ & 0.042 \\
\hline \multirow[t]{2}{*}{ blood glucose } & Physicians & $3.4(3.6)$ & $3.8(3.9)$ & 0.012 \\
\hline & Nurses & $3.4(3.6)$ & $3.3(3.4)$ & 0.705 \\
\hline \multirow[t]{3}{*}{ Impact of diabetes } & Pharmacists & $3.4(3.6)$ & $3.7(3.6)$ & 0.164 \\
\hline & Physicians & $3.7(3.7)$ & $3.7(3.8)$ & 0.744 \\
\hline & Nurses & $3.2(3.1)$ & $3.4(3.2)$ & 0.58 \\
\hline \multirow{3}{*}{$\begin{array}{l}\text { Autonomy of } \\
\text { diabetes for } \\
\text { patient }\end{array}$} & Pharmacists & $3.0(3.3)$ & $3.7(3.7)$ & 0.182 \\
\hline & Physicians & $3.4(3.5)$ & $3.7(3.6)$ & 0.51 \\
\hline & Nurses & $3.3(3.3)$ & $3.4(3.4)$ & 0.83 \\
\hline
\end{tabular}


For the subscale on the value of tight blood glucose control, the study found two statistically significant differences between physicians and nurses ( $p=0.001)$, and significant differences were found between pharmacists and nurses $(p=0.037)$.

Table 5: HCPs attitude towards seriousness of diabetes and value of tight blood glucose levels (posttest)

\begin{tabular}{llcc}
\hline Item & $\begin{array}{l}\text { HCPs' } \\
\text { category }\end{array}$ & $\begin{array}{c}\text { Post-test } \\
\text { mean } \\
\text { (median) }\end{array}$ & $\begin{array}{c}{ }^{*} \boldsymbol{P} \text { - } \\
\text { value }\end{array}$ \\
\hline \multirow{4}{*}{ Seriousness of } & Physicians & $3.1(3.0)$ & \\
diabetes & Pharmacists & $3.1(3.3)$ & 0.059 \\
& Nurses & $2.8(2.8)$ & 0.201 \\
& Physicians & $3.3(3.3)$ & \\
& Nurses & $2.8(2.8)$ & 0.001 \\
& Pharmacist & $3.7(3.6)$ & 0.309 \\
Value of tight & Physicians & $3.8(3.9)$ & \\
blood glucose & Pharmacists & $3.7(3.6)$ & 0.037 \\
& Nurses & $3.3(3.4)$ & \\
& Physicians & $3.8(3.9)$ & 0.001 \\
& Nurses & $3.3(3.4)$ & \\
\hline * Mann & &
\end{tabular}

* Mann-Whitney U test

\section{DISCUSSION}

CE programs that address the importance of healthcare professionals' attitudes and increases their diabetes care knowledge leads to an improvement in the quality of care for diabetes patients [23]. The present study evaluated the changes in HCPs' attitudes and found that their attitudes towards diabetes care improved after a CE program.

In response to the statements on the need for special training, most of the HCPs already had a positive attitude before attending the CE, and their attitude improved after the CE. This showed that HCPs felt that they needed to update their knowledge and skills through special training in the methods of providing patient education and patient counseling, as well as using motivational interviewing techniques to change patients' behavior [22].

This study recorded a mean attitude score of 4.2 out of a maximum of five, which implied that HCPs agreed to the need for special training. This finding is slightly lower than Anderson and colleagues who reported a mean attitude score of over 4.6 [22]. Since both this study and Anderson's utilized the same measurement (DAS-3), the latter's finding showed that their participants had a better attitude toward the need for training. This difference could be related to the different requirements in Michigan, the USA where Anderson and colleagues carried out their study.

In Michigan, all HCPs involved in diabetes care are required to be certified practitioners, whereas there is no such requirement in Yemen. A more recent study by Gagliardino et al [24] in Argentina used DAS-3 to measure the attitude of HCPs and diabetes patients toward diabetes care. Although Argentina is also a developing country and does not require certified practitioners, a slightly better attitude score (4.5) was recorded compared with the finding of this study. The difference can be attributed to the difference in the study subjects. Gagliardino et al included all types of HCPs, including podiatrists, social workers, and nutritionists as well as diabetic patients who had attended the diabetes education program [24].

Evaluation of the attitude of each HCP group towards the need for special training found that all physicians, nurses, and pharmacists had a similar attitude score of 4.2. Sharp and colleagues [23] found slightly higher attitude scores among physicians in the USA (4.66) compared to our finding (4.2). However, the pharmacists' attitude toward the need for special training is comparable with the study in Taiwan by Chen et al where they found the pharmacists' attitude score was 4.35 [24]. As noted earlier, these two findings supported our argument that those practitioners from developed countries with mandatory certification tend to report better attitude scores than developing countries without certification requirements.

The attitudes of the HCPs towards the level of seriousness of diabetes will eventually influence their decisions in patient management. Practitioners will pay more attention if they believe that the patient's condition is serious. This study found that the HCPs showed a negative attitude toward the seriousness of diabetes before the CE (pre-test) with a mean score of 2.99. After the CE, the attitude score improved slightly but was still within the neutral range with a mean score of 3.1. This finding shows that HCPs in Yemen do not consider diabetes a serious disease. This could be related to the background of the HCPs.

In this study, the physicians, pharmacists, and nurses were all general practitioners, not diabetes care specialists. Therefore, they may have encountered many serious acute illnesses that needed immediate attention in their practice, but overlooked the potentially dangerous complications of chronic disease states. Anderson and Sharp [22,23] used subjects from 
diabetic care clinics and those attending a diabetes CE. Their scores were higher than those in this study.

Analysis based on HCP groups indicate that physicians scored higher in this area than nurses and pharmacists, although the difference was not significant. This finding does not correspond to those which found HCPs other than physicians scored higher on their attitudes towards the seriousness of diabetes [22,23].

The value of tight blood glucose control is very important in the management of diabetes. The United Kingdom Prospective Diabetes Study (UKPDS) discovered that those patients in the intensive therapy group had better outcomes [23]. Therefore, the attitudes of the HCPs towards blood glucose control should be scientifically correct in order for them to advise their patients properly. This study found that the HCP attitudes towards the importance of blood glucose control were neutral prior to CE (3.3).

The attitude of the HCPs improved significantly to 3.7 after the CE program. Analysis of HCP groups found that physicians (3.8) had a better attitude than pharmacists (3.7) and nurses (3.3). This finding is related to the role of physicians and pharmacists in diabetes management where both professions are involved in controlling patients' drug treatments and monitoring their outcomes. This finding is similar to the finding of [24] Gagliardino but lower than previously reported [22-25].

The fourth subscale measured the HCPs' attitudes towards the psychosocial impact of diabetes on patients. This is very important because it measures the concern of the HCPs about the patient's daily life. This study discovered that the HCPs had a higher than neutral attitude score (mean $=3.5$ at pre-test) and (mean=3.6 at post-test). The increase in attitude, however, was not significant $(p=0.098)$.This finding corresponds to that of [24,25] Gagliardino and Chen, but is lower than those of $[22,25]$ Anderson and Sharp.

\section{Attitude toward the autonomy of the diabetes patients}

HCPs' beliefs in the role of patients in the management of diabetes were measured by their attitude towards the autonomy of the patients. Their positive attitudes indicated their inclination towards empowering patient empowerment related to the management of their problems. $(p=0.023)$ to 3.7 after the intervention. This result was similar to previously published studies by Sharp et al [23,24] but the attitude score was lower than the study published by Anderson. This finding is superior to that of Anderson et al [22] and Gagliardino et al [24] who reported attitude scores towards patient autonomy were only 2.79 .

Analysis of the HCP groups indicate that the attitude scores of the physicians, pharmacists, and nurses before the CE were almost similar (3.3 and 3.4), but the nurses showed the lowest improvement in attitude scores (3.3 to 3.4) compared with pharmacists and physicians (3.3 and 3.4 to 3.7 , respectively). This finding is comparable to the findings of Sharp et al [23,25]. Both studies showed improvements in the attitude scores towards patient autonomy, but the improvements were not significant.

This finding is supported by previous studies that found a significant effect of diabetes education programs on the attitudes of healthcare professionals [23,25].

\section{Limitations of study}

This study has several limitations. One of the limitations is the study design which used onegroup for both the pre- and post-intervention without a control group. The use of a control group would make it possible to avoid biased results.

The second limitation is the small sample size. This problem arose because the study used a convenient sampling method and relied on the consent of the HCPs. Although the majority of the HCPs (pharmacists, physicians, and nurses) in Mukalla city were invited, many of them did not attend. In addition, the research was conducted in one outpatient diabetic clinic; therefore, the results of this study cannot be generalized beyond Mukalla city.

The third limitation is that the English language was the medium of communication used in the CE program. As Arabic is the main language used in Yemen, the use of the English language could be a barrier to the study's effectiveness.

\section{CONCLUSION}

This study found that healthcare professionals have positive attitudes toward diabetes. Physicians were more aware of the seriousness of diabetes than other healthcare professional groups (pharmacists and nurses), while nurses ranked lowest in this regard. Therefore, nurses and pharmacists should receive more education programs on diabetes. 


\section{DECLARATIONS}

\section{Conflict of Interest}

No conflict of interest associated with this work.

\section{Contribution of Authors}

The authors declare that this work was done by the authors named in this article and all liabilities pertaining to claims relating to the content of this article will be borne by them.

\section{REFERENCES}

1. Shahla L, Vasudev R, Chitturi C, Rodriguez C, Paul N. Diabetes mellitus treatment-Related medical knowledge among health care providers. Diabetes \& metabolic syndrome 2017; 11 (1): 69 -72.

2. Alqurashi KA, Aljabri KS, Bokhari SA. Prevalence of diabetes mellitus in a Saudi community. Ann Saudi Med 2011; 31(1): 19-23.

3. Powers MA, Bardsley J, Cypress M, Duker P, Funnell $M M$, Fischl AH, Maryniuk MD, Siminerio L, Vivian E. Diabetes Self-Management Education and Support in Type 2 Diabetes: A Joint Position Statement of the American Diabetes Association, the American Association of Diabetes Educators, and the Academy of Nutrition and Dietetics. J Acad Nutr Diet. 2015; 115 : 1323-334

4. Funnell MM, Brown TL, Childs BP, Haas LB, Hosey GM, Jensen B, Maryniuk $M$,

5. Peyrot M, Piette JD, Reader D, Siminerio LM, Weinger K, Weiss MA. National standards for diabetes selfmanagement education. Diabetes Care 2008; 31 Suppl 1: $S 97-104$

6. Pace $A E$, Ochoa-Vigo $K$, Caliri MH, Fernandes $A P$. Knowledge on diabetes mellitus in the self-care process. Rev Lat Am Enfermagem 2006; 14(5): 728-734.

7. Odili VU and Oparah AC. Attitudes of health care professionals towards diabetes. West Afr J Pharm 2012; 23: 54-59.

8. Donnelly MB, Anderson RM. The role related attitudes of Physicians, Nurses, and Dieticians in the treatment of diabetes. Medical Care 1990; 28: 175-179

9. Schapansky LM, Johnson JA, Pharmacists attitudes towards diabetes. J Am Pharm Assoc 2000; 40: $371-7$

10. Jacques $C H$, Jones $R C$, Houts $P$, Lynch JC, Dwyer $K$. Continuing medical education on diabetes by primary care physicians. Diabetes Educ 1991; 17: 269-273.

11. Weinberger M, Cohen SJ, Mazzuca SA. The role of physicians' knowledge in effective diabetes management. Soc Sci Med 1984; 19: 965-969.

12. Chen HY, Lee TY, Huang WT, Chang CJ, Chen CM. The short term impact of a continuing education program on pharmacists' knowledge and attitude toward diabetes. Ann J Pharmaceut Educ 2004; 68 article 121.

13. Sharp LK, Lipsky MS. Continuing medical education and attitudes of health care providers towards treating diabetes. J Contin Educ Health Professional 2002; 22: 103-112

14. Sharp LK, Lipsky MS. The short term impact of continuing medical education program on providers' attitudes toward treating diabetes. Diabetes Care 1999; 22 1929-1932.

15. Egede LE, Michel Y. Attitudes of Internal Medicine Physicians towards Type 2 Diabetes. South Med J. 2002; 9-5(1).

16. Younis WS, Campbell S, Slaack MK. Pharmacists' attitudes toward diabetes and their involvement in diabetes education. Ann Pharmacother 2001; (35): 841 845

17. Schapansky LM, Johnson JA, Pharmacists attitudes towards diabetes. J Am Pharm Assoc 2000; 40: 371377.

18. Plake KS, Chestnut RJ, Biebighauser S. impact of a diabetes certificate programme on pharmacists' diabetes care activities. American Journal of pharmaceutical Education 2003; 67, article 116.

19. Davidson MB, Karlan VJ, Hair TL. Effect of a pharmacistmanaged diabetes care program in a free medical clinic. Am J Med Qual 2000; 15: 137-142.

20. Lau SL, Debarm R, Thomas N, Asha HS, Vasan KS, Alex $R G$, et al. Healthcare planning in north-east India: $A$ survey on diabetes awareness, risk factors and health attitudes in a rural community. $J$ Assoc Physicians India 2009; 57: 305-309.

21. Shaini GS, Venkatesan L, Ben A. Effectiveness of structured teaching on home care management of diabetes mellitus. Nurs J India 2007; 98: 197-199.

22. World Health Organization, and Council for International Organizations of Medical Sciences. International ethical guidelines for health-related research involving humans, 2016.

23. Anderson RM, Fitzgerald JT, Funnell MM, Gruppen $L D$. The third version of the Diabetes Attitude Scale. Diabetes Care 1998; 21: 1403-1407.

24. Sharp LK, Lipsky MS. The short-term impact of a continuing medical education program on providers. Diabetes Care. 1999; 22: 1929.

25. Gagliardino JJ, González C, Caporale JE. Diabetes Education Study Group of Argentina. The diabetesrelated attitudes of health care professionals and persons with diabetes in Argentina. Rev Panam Salud Publica 2007; 22: 304-307.

26. Chen $H-Y$, Lee $T-Y$, Huang $W-T$, Chang $C-J$ \& Chen $C-$ $M$. The Short-Term Impact of a Continuing Education Program on Pharmacists' Knowledge and Attitudes Toward Diabetes. Amer J Pharmaceut Edu.2004; 68(5): 121. 